\title{
BROAD SPECTRUM DETECTION OF ANTIBIOTIC RESIDUES IN POULTRY MEAT BY A MULTI-PLATE ASSAY
}

\author{
Watkins, H. S., Kožárová, I. \\ Institute of Meat Hygiene and Technology \\ University of Veterinary Medicine and Pharmacy in Košice, Ko menského 73, 04181 Košice \\ Slovakia
}

ivona.kozarova@uvlf.sk

\section{ABSTRACT}

The objective of this study was to use the "Screening test for antibiotic residues" (STAR) as a broad-spectrum detection method for antibiotic residues in poultry meat. The STAR method is a microbiological inhibition assay (a five plate test) where the development of inhibition zones (IZs) indicates the presence of antibiotic residues in meat samples. By using the STAR method, in a total of 13 poultry products providing 18 meat samples (14 muscle and 4 skin) and 18 corresponding juice samples, 11 out of the 18 samples were positive for containing antibiotic residues. Based on muscle alone (which is the matrix validated for use in the STAR method), 6 of the 14 muscle samples were positive for antibiotic residues. The STAR method as a screening technique proves advantageous as it is relatively easy to perform and of a low cost. Furthermore, the STAR method not only indicates the presence or absence of antibacterial substances, but simultaneously, a positive sample gives an indication of the antibiotic family present due to the use of five different bacterial test organisms. Families of antibiotics pre- identified due to positive samples in the results of this study include aminoglycosides (one out of 18), beta-lactams and sulphonamides ( 6 out of 18), and macrolides (5 out of 18). Such pre-identification of the antimicrobial families allows for a targeted confirmatory analysis. However, one could argue that the STAR method is laborious and time consuming. Overall, given the potential for false positive/negative results, further confirmatory method analysis of the samples must be performed to ensure that the results and conclusions drawn here are true.

Key words: antibiotics; meat; residues; screening

\section{INTRODUCTION}

Throughout the world, there is an emerging public health crisis and a growing concern regarding the potential for the development of antimicrobial resistance (AMR) that can occur as a result of the selective pressure and dissemination of resistance caused by unscrupulous misuse and inappropriate antimicrobial usage $[1,9,13,19]$. Over time, 
the restriction of antibiotic usage has been encouraged, if not enacted through legislation, in an attempt to prevent such AMR development due to non-rational veterinary antimicrobial use [10]. However, despite this, by 2030, the global use of antimicrobials in food animal production is expected to increase by $67 \%$ compared to the 2010 usage levels $[18,19]$.

Antimicrobial usage within the veterinary industry can result in the presence of antimicrobial residues in food of animal origin [15]. Such presence of antimicrobial residues can result in direct toxicity or indirectly in AMR. Antimicrobial residue levels in the edible tissues of livestock, including poultry, should be monitored via detection methods (screening and subsequent confirmation) and assessed regularly to ensure that the food of animal origin is safe and wholesome for consumers and does not contain antimicrobial residues at levels which exceed the established Maximum Residue Limits (MRLs) as defined by legislation $[4,13]$.

The purpose of screening methods is to rapidly identify a desired analyte (antibiotic residues in this instance) where present, using ideally a simple (meaning requiring minimal resources and able to be performed by an unskilled personnel) and high throughput method [2]. Where a screening method results in a positive result for a sample, a confirmation is performed to determine if the sample is indeed positive (for antibiotic residues), identify the substance(s) present; and, in relation to antibiotic residues present in the meat, determine if these residues are at levels above the MRL which would result in condemnation of the meat product [8]. Plate tests are microbiological inhibition assays used as the main screening method for antibiotics in slaughter animals in Europe [15]. Plate tests rely on the principle that when antimicrobial (antibiotic) residue-containing samples are applied, the growth of the bacteria will be impeded resulting in the formation of inhibition zones (IZs) as a result of diffusion of the antibiotic from the sample $[2,15]$.

This study concerned the use of the STAR method as a broad spectrum multi-plate assay method for the detection of antibiotic residues in poultry meat. By its completion we aimed to determine whether antibiotic residues were present in the samples and also to evaluate the STAR method as a screening method for a broad spectrum detection of antibiotic residues. We also wanted to compare and draw conclusions from the results given by the use of dif- ferent matrices, despite the STAR method being validated only for use in muscle (and milk).

\section{MATERIALS AND METHODS}

\section{Sample material}

A total of 13 poultry products from the UK and Ireland were used for residues analysis. The 18 samples with sample numbers 1 and 6-9 being thigh; sample numbers $3-5,10-12$ and 15 being breast; sample number 2 being a chicken portion; sample number 13 being a wing; and sample numbers $14,16-18$ being skin which was used as a different matrix for 4 products in addition to muscle (namely sample numbers 15, 8, 7 and 6, respectively). For one product, the muscle from 2 different locations (breastsample number 15; wing-sample number 13) were used. For all samples, in addition to the skin or muscle matrix used, also the juices were collected for testing.

\section{Sample analysis}

The study used the STAR method in the manner prescribed by the STAR protocol of $\mathrm{G}$ a u d in and F u s e1 i e r [5]. The test organisms used were: Bacillus stearothermophilus ATCC 10149, grown at pH 7.4 (with the addition of Trimethoprim at a $1 \%$ concentration equalling $0.005 \mu \mathrm{g}$. $\mathrm{ml}^{-1}$ agar medium), Bacillus cereus ATCC 11778, grown at pH 6, Bacillus subtilis B. G. A., grown at pH 7.2, Escherichia coli ATCC 11303, grown at $\mathrm{pH} 8$, and Kocuria rhizophila ATCC 9341 (formerly Micrococcus luteus), grown at pH 8. Prior to use, the meat samples were stored at $-18{ }^{\circ} \mathrm{C}$ (deepfreeze freezer temperature) and the removal of samples for analysis from the freezer occurred to allow slight defrosting prior to sample preparation. For each muscle sample, a sterile cork borer of $8 \mathrm{~mm}$ diameter was used to remove a cylindrical plug measuring approximately $2 \mathrm{~cm}$ in length (and $8 \mathrm{~mm}$ in diameter). Then the muscle sample was gently pushed out from the borer (using forceps) and cut into slices of approximately $2 \mathrm{~mm}$ thick, using a sterile scalpel. Where the skin was attainable, it was removed from the corresponding muscle via manual manipulation and scissors were used to cut a small section from the skin similar in size and shape to the muscle slices taken. The prepared tissue (muscle or skin) slices were transferred to the test plates using sterile forceps. The juice was obtained from the skin and muscle samples via thawing the tissue samples 
(placed in $15 \mathrm{ml}$ capped plastic graduated cylinder centrifuge tubes with the cap loosened in the test tube racks) using a microwave oven set on the defrost setting. For juices, antibiotic test paper discs (diameter of $9 \mathrm{~mm}$ from Albert Lab Science, Germany) were used to soak up approximately $30 \mu \mathrm{l}$ from the juice obtained for each sample and then placed onto the test plates using sterile forceps. Onto each plate, 3 tissue (muscle or skin) slices were placed as well as the juice-soaked test paper discs corresponding to the same product and type of sample from which these slices were obtained; resulting in 6 samples per plate. Testing occurred in duplicate. Placement was aimed to be approximately $1 \mathrm{~cm}$ away from the rim of the plate and other samples. The prepared plates inoculated with test bacteria and with samples were incubated as follows: Bacillus stearothermophilus incubated at $55^{\circ} \mathrm{C}$ for 15 hours, Bacillus cereus incubated at $30^{\circ} \mathrm{C}$ for 18 hours, Bacillus subtilis incubated at $30{ }^{\circ} \mathrm{C}$ for 18 hours, Escherichia coli incubated at $37^{\circ} \mathrm{C}$ for 24 hours, and Kocuria varians incubated at $37^{\circ} \mathrm{C}$ for 24 hours.

\section{Evaluation of results}

For each plate, individual tissue samples (skin or meat) and juice-soaked test paper discs were visually analysed for the presence or absence of IZs. The presence of an IZ indicated the diffusion of antimicrobial substances present within the sample/juice for which the test organism inoculated on the test plate was sensitive; resulting in the inhibition of test organism growth creating the IZ seen. Where the clear IZs were present, the zones were measured using a digital caliper (with a precision of $0.01 \mathrm{~mm}$ ) at 3 points from the boundary of the tissue sample or the test paper disc to the outer limits of the IZ. The measurements were recorded and a mathematical average was taken to determine one value (from 3) for each IZ where present. Samples were deemed positive where an IZ equal to or more than a width of $2 \mathrm{~mm}$ was found on the test plates inoculated with four of the test organisms: Bacillus cereus, Bacillus subtilis, Escherichia coli and Kocuria rhizophila. For the test plate inoculated with Bacillus stearothermophilus, samples were deemed positive where an IZ equal to or more than a width of $4 \mathrm{~mm}$ was found. According to the protocol of $\mathrm{G}$ a u d i n and Fu s e li e r [5], if at least one plate out of the 5 plates containing different test bacteria was positive, the sample was considered overall positive for containing antibacterial residues. Positive (quality) control plates inoculated with test organisms were validated for systematic respect of operating conditions using standard solutions containing reference antibiotics.

\section{RESULTS AND DISCUSSION}

Based on all matrices used, 11 out of the 18 samples were positive for containing antibiotic residues. Based on the muscle as the matrix alone (which is the matrix validated for use in the STAR method), 6 of the 14 muscle samples were positive for containing antibiotic residues. Based on additional matrices not validated for use within the STAR method, 3 of the 4 skin samples and 3 of the 18 juice samples (juice as obtained from meat samples/muscle and skin) were positive for containing antibiotic residues. Note that no IZs were produced when Bacillus cereus was the organism, nor when meat was the matrix used when Bacillus subtilis was the organism, and nor where juice was the matrix used when Escherichia coli was the organism. Table 1 shows a summary of the overall results for the samples using the STAR method. Table 2 gives the results of the STAR method based on the mean inhibition zone measured (in $\mathrm{mm}$ ) with standard deviation (SD) for all organisms and all plates. Figures $1-5$ present the plates for sample numbers $1-6$ for each individual organism (Bacillus stearothermophilus, Bacillus cereus, Bacillus subtilis, Escherichia coli and Kocuria rhizophila, respectively).

According to the plates for Bacillus stearothermophilus, based on meat (muscle and skin) as the matrix, IZs were produced for all samples. Furthermore, based on juice as the matrix for the B. stearothermophilus plates, IZs were produced for 5 of the 18 samples (sample numbers $3,4,6$, 8 and 9); with positive results given for 3 of the 14 muscle samples (sample numbers 1, 6, and 13) and 3 of the 4 skin samples (sample numbers 14, 16 and 17). For the B. stearothermophilus plates, based on SD values and given the spread of data, one could argue that sample numbers 6 and 14, where muscle and skin was used as the matrix respectively, could be false positives; whilst sample number 18 , where skin was used as the matrix, could be a false negative. According to the plates for Bacillus cereus, no IZs were produced for any of the samples on any of the plates. According to the plates for Bacillus subtilis, an IZ of a size greater than $2 \mathrm{~mm}$ indicating a positive result was produced for sample number 3 with juice as the matrix. No other IZs were produced for the B. subtilis plates. According to 
Table 1. Summary table giving the overall results for the samples using the STAR method

\begin{tabular}{|c|c|c|c|c|c|c|c|c|c|c|c|}
\hline \multirow{3}{*}{$\begin{array}{c}\text { Organism } \rightarrow \\
\text { Matrix } \rightarrow \\
\text { Sample no. } \downarrow\end{array}$} & \multirow{3}{*}{$\begin{array}{l}\text { Overall } \\
\text { Result }\end{array}$} & \multicolumn{2}{|c|}{$\begin{array}{l}\text { Bacillus } \\
\text { stearothermophilus }\end{array}$} & \multicolumn{2}{|c|}{ Bacillus cereus } & \multicolumn{2}{|c|}{ Bacillus subtilis } & \multicolumn{2}{|c|}{ Escherichia coli } & \multicolumn{2}{|c|}{ Kocuria rhizophila } \\
\hline & & Juice & Meat & Juice & Meat & Juice & Meat & Juice & Meat & Juice & Meat \\
\hline & & & & & & & & & & & \\
\hline 1 Thigh & Positive & - & + & - & - & - & - & - & - & - & - \\
\hline 2 Portion & Positive & - & - & - & - & - & - & - & - & + & - \\
\hline 3 Breast & Positive & - & - & - & - & + & - & - & - & - & - \\
\hline 4 Breast & Positive & - & - & - & - & - & - & - & - & + & - \\
\hline 5 Breast & Negative & - & - & - & - & - & - & - & - & - & - \\
\hline 6 Thigh & Positive & - & + & - & - & - & - & - & - & - & - \\
\hline 7 Thigh & Negative & - & - & - & - & - & - & - & - & - & - \\
\hline 8 Thigh & Negative & - & - & - & - & - & - & - & - & - & - \\
\hline 9 Thigh & Negative & - & - & - & - & - & - & - & - & - & - \\
\hline 10 Breast & Negative & - & - & - & - & - & - & - & - & - & - \\
\hline 11 Breast & Positive & - & - & - & - & - & - & - & - & - & + \\
\hline 12 Breast & Negative & - & - & - & - & - & - & - & - & - & - \\
\hline 13 Wing & Positive & - & + & - & - & - & - & - & - & - & + \\
\hline 14 Skin & Positive & - & + & - & - & - & - & - & - & - & - \\
\hline 15 Breast & Positive & - & - & - & - & - & - & - & - & - & + \\
\hline 16 Skin & Positive & - & + & - & - & - & - & - & - & - & - \\
\hline 17 Skin & Positive & - & + & - & - & - & - & - & - & - & - \\
\hline 18 Skin & Negative & - & - & - & - & - & - & - & - & - & - \\
\hline
\end{tabular}

the plates for Escherichia coli, based only on muscle as the matrix, IZs were produced for 4 of the 14 samples (sample numbers 2, 4, 5 and 6). None of these IZs produced were of a size great enough to result in a positive result; and no other IZs were produced for the E. coli plates. According to the Kocuria rhizophila plates, based on muscle as the matrix, IZs were produced for 10 of the 14 samples (sample numbers $2-6,10-13$ and 15). Furthermore, based on juice as the matrix for the K. rhizophila plates, IZs were produced for 8 of the 18 samples (sample numbers $1-6,8$ and 15). Based on skin as the matrix for the K. rhizophila plates, an IZ was produced for one of the 4 samples (sample number 14). For the K. rhizophila plates, positive results were given for 3 muscle samples (sample numbers 11, 13 and 15) and 2 juice samples (sample number 2 and 4 ). For the K. rhizophila plates, based on SD values and given the spread of data, one could argue that sample numbers 2 (juice), 11 (muscle) and 13 (muscle) could be false positives; whilst sample numbers 1 and 15, where juice was used as the matrix, could be false negatives.

The STAR method detected the presence of inhibitory substances and so gave positive results for some samples; and in doing so, it detected antibiotics from the families including aminoglycosides (indicated by the B. subtilis plates), $\beta$-lactams and sulphonamides (indicated by the B. stearothermophilus plates), and macrolides (indicated by the K. rhizophila plates). The STAR method is validated for use only in the case that muscle samples and milk are the matrix in accordance with the European Decision 2002/657/EC [3] and with an internal guideline of validation as defined by the authors of the validation paper $[6,7]$. As such, the positive results given by juice samples 
Table 2. Results of screening for the presence of antibiotic residues in samples using the STAR method for all organisms and all plates

\begin{tabular}{|c|c|c|c|c|c|c|c|c|c|c|}
\hline \multirow{2}{*}{$\begin{array}{l}\text { Organism } \\
\text { Matrix } \rightarrow\end{array}$} & \multicolumn{2}{|c|}{ Bacillus stearothermophilus } & \multicolumn{2}{|c|}{ Bacillus cereus } & \multicolumn{2}{|c|}{ Bacillus subtilis } & \multicolumn{2}{|c|}{ Escherichia coli } & \multicolumn{2}{|c|}{ Kocuria varians } \\
\hline & Juice & Meat & Juice & Meat & Juice & Meat & Juice & Meat & Juice & Meat \\
\hline $\begin{array}{c}\text { Sample } \\
\text { no. } \downarrow\end{array}$ & $\begin{array}{l}\text { Mean } \\
\quad I Z \\
\pm S D\end{array}$ & $\begin{array}{c}\text { Mean } \\
\text { IZ } \\
\pm \text { SD }\end{array}$ & $\begin{array}{c}\text { Mean } \\
\text { IZ } \\
\pm S D\end{array}$ & $\begin{array}{c}\text { Mean } \\
\text { IZ } \\
\pm \text { SD }\end{array}$ & $\begin{array}{c}\text { Mean } \\
\text { IZ } \\
\pm \text { SD }\end{array}$ & $\begin{array}{c}\text { Mean } \\
\text { IZ } \\
\pm \text { SD }\end{array}$ & $\begin{array}{c}\text { Mean } \\
\text { IZ } \\
\pm \text { SD }\end{array}$ & $\begin{array}{c}\text { Mean } \\
\text { IZ } \\
\pm S D\end{array}$ & $\begin{array}{c}\text { Mean } \\
\text { IZ } \\
\pm S D\end{array}$ & $\begin{array}{c}\text { Mean } \\
\text { IZ } \\
\pm S D\end{array}$ \\
\hline 1 Thigh & - & $4.01 \pm 0.51$ & - & - & - & - & - & - & $1.87 \pm 0.95$ & - \\
\hline 2 Portion & - & $1.74 \pm 0.99$ & - & - & - & - & - & $0.69 \pm 0.19$ & $2.33 \pm 0.34$ & $1.04 \pm 0.11$ \\
\hline 3 Breast & $0.84 \pm 0.35$ & $0.99 \pm 0.44$ & - & - & $4.38 \pm 0.21$ & - & - & - & $0.88 \pm 0.58$ & $1.03 \pm 0.25$ \\
\hline 4 Breast & $1.35 \pm 0.29$ & $3.65 \pm 0.34$ & - & - & - & - & - & $0.53 \pm 0.02$ & $2.49 \pm 0.35$ & $1.43 \pm 0.30$ \\
\hline 5 Breast & - & $1.29 \pm 0.12$ & - & - & - & - & - & $0.85 \pm 0.20$ & $1.42 \pm 0.10$ & $1.44 \pm 0.44$ \\
\hline 6 Thigh & $1.95 \pm 0.26$ & $4.42 \pm 0.72$ & - & - & - & - & - & $0.60 \pm 0.03$ & $1.08 \pm 0.50$ & $1.04 \pm 0.20$ \\
\hline 7 Thigh & - & $2.15 \pm 0.16$ & - & - & - & - & - & - & - & - \\
\hline 8 Thigh & $1.16 \pm 0.82$ & $3.28 \pm 0.03$ & - & - & - & - & - & - & $0.60 \pm 0.28$ & - \\
\hline 9 Thigh & $0.55 \pm 0.16$ & $3.46 \pm 0.12$ & - & - & - & - & - & - & - & - \\
\hline 10 Breast & - & $2.23 \pm 0.40$ & - & - & - & - & - & - & - & $1.43 \pm 0.47$ \\
\hline 11 Breast & - & $2.41 \pm 0.22$ & - & - & - & - & - & - & - & $2.20 \pm 0.44$ \\
\hline 12 Breast & - & $1.26 \pm 0.12$ & - & - & - & - & - & - & - & $0.64 \pm 0.15$ \\
\hline 13 Wing & - & $5.34 \pm 0.68$ & - & - & - & - & - & - & - & $2.39 \pm 0.90$ \\
\hline 14 Skin & - & $4.31 \pm 1.19$ & - & - & - & - & - & - & - & $1.47 \pm 0.24$ \\
\hline 15 Breast & - & $2.91 \pm 0.52$ & - & - & - & - & - & - & $1.67 \pm 0.44$ & $3.61 \pm 0.27$ \\
\hline 16 Skin & - & $6.81 \pm 1.18$ & - & - & - & - & - & - & - & - \\
\hline 17 Skin & - & $4.40 \pm 0.11$ & - & - & - & - & - & - & - & - \\
\hline 18 Skin & - & $3.86 \pm 1.14$ & - & - & - & - & - & - & - & - \\
\hline
\end{tabular}

Mean IZ-Average Inhibition Zone ( $\mathrm{mm}$ ); SD—standard deviation; Bold numerals indicate a positive result

and skin samples are questionable; especially whereas it is known that the matrix used can impact upon the results given $[14,17]$. The results show evident of a discrepancy between whether an IZ is produced and whether an IZ produced yields of a positive result based upon the type of matrix used when comparing muscle vs. juice vs. skin. Also, given the SD and the spread of data, false negative and false positive results are possible; with a false negative being of a more significant concern given where a negative result is produced, means no further testing is performed.

Given the use of calipers for the measurement of IZs associated with antibiotic residue presence, the STAR method could be defined as a semi-quantitative method used as a qualitative screening assessment; where the diameter of the IZ produced theoretically correlates and so is directly proportional to the level/concentration of antibiotic residues found within a sample $[11,12,16]$. Note that there is some subjectivity in relation to determining at which points to measure on an IZ and also the respective distance of the IZ. This subjectivity is limited given that 3 points are measured and then the average is taken to give the IZ size; however, this could prove significant in relation to the SD in cases where the results could be deemed as false positives or false negatives.

The STAR method proved of value as a screening method due to its relative ease to perform, low cost, robustness and ability to detect a wide range of antibiotics at a level of satisfactory sensitivity. However, the STAR method proved laborious and time consuming. Furthermore, the STAR 

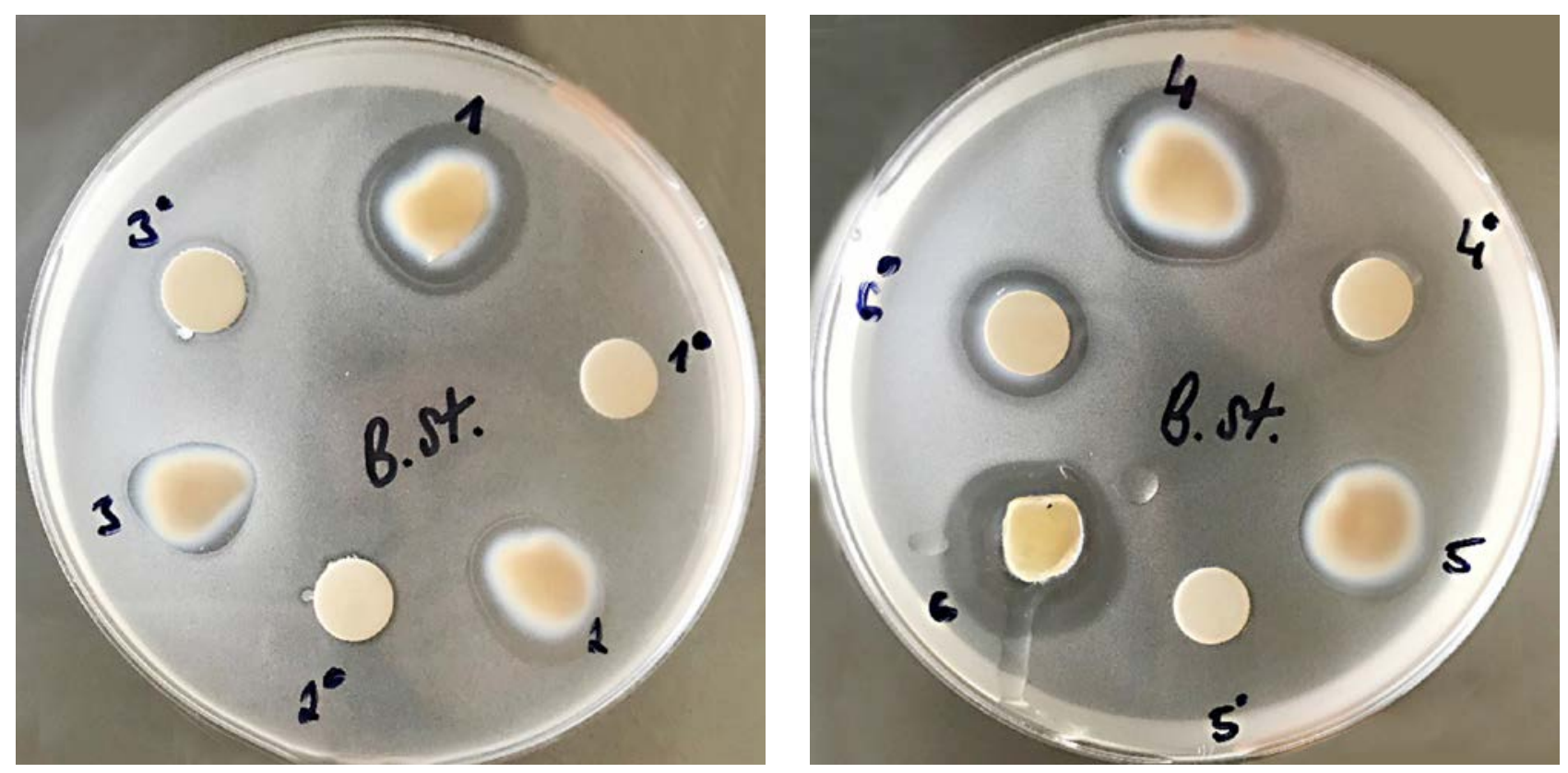

Fig. 1. Images showing the Bacillus stearothermophilus plates post-incubation for sample numbers $1-6$ where IZs are present for all meat samples and for samples $3^{\circ}, 4^{\circ}$ and $6^{\circ}$ where juice was the matrix
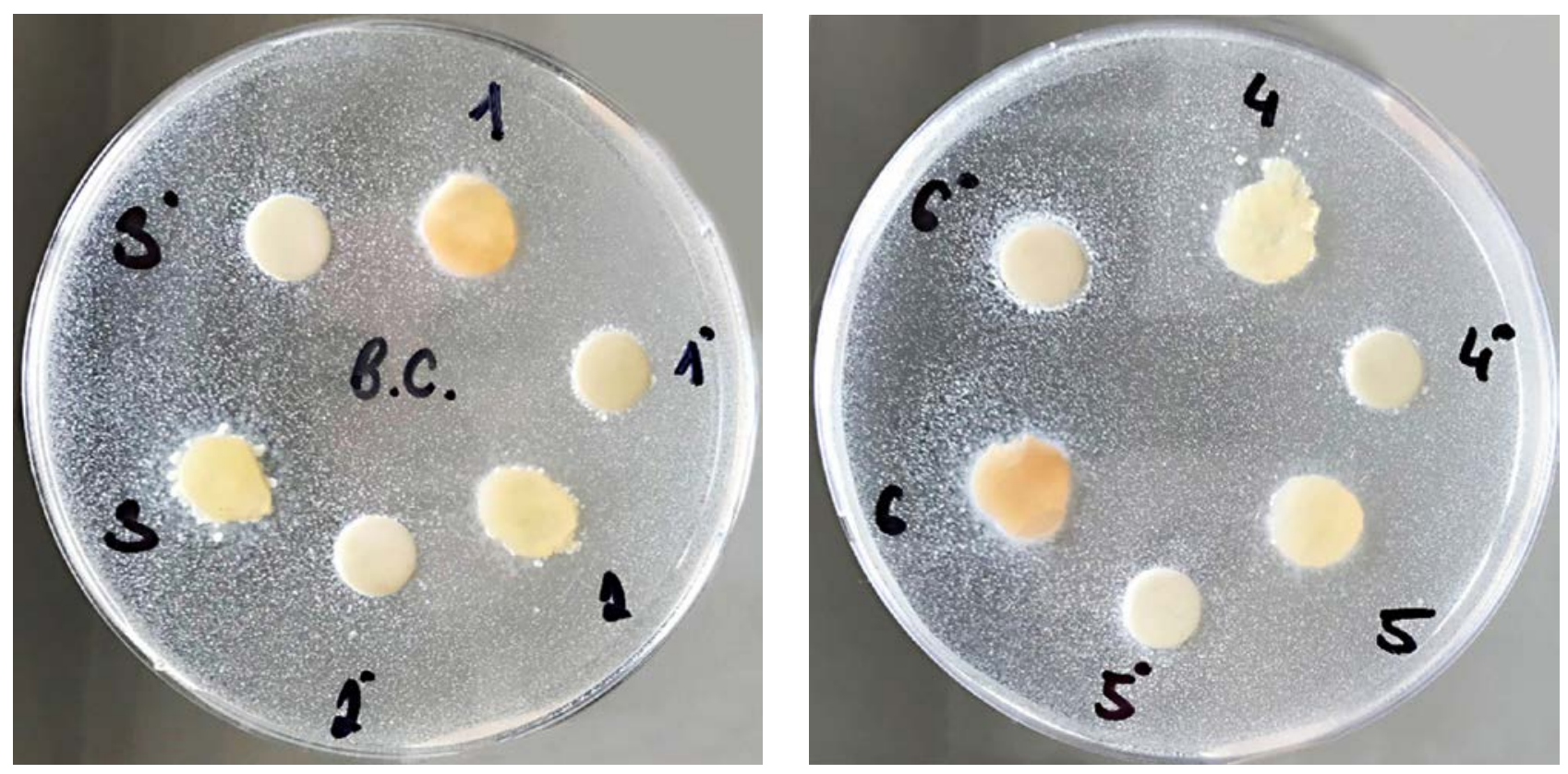

Fig. 2. Images showing Bacillus cereus plates post-incubation for sample numbers $1-6$ (no IZs present) 

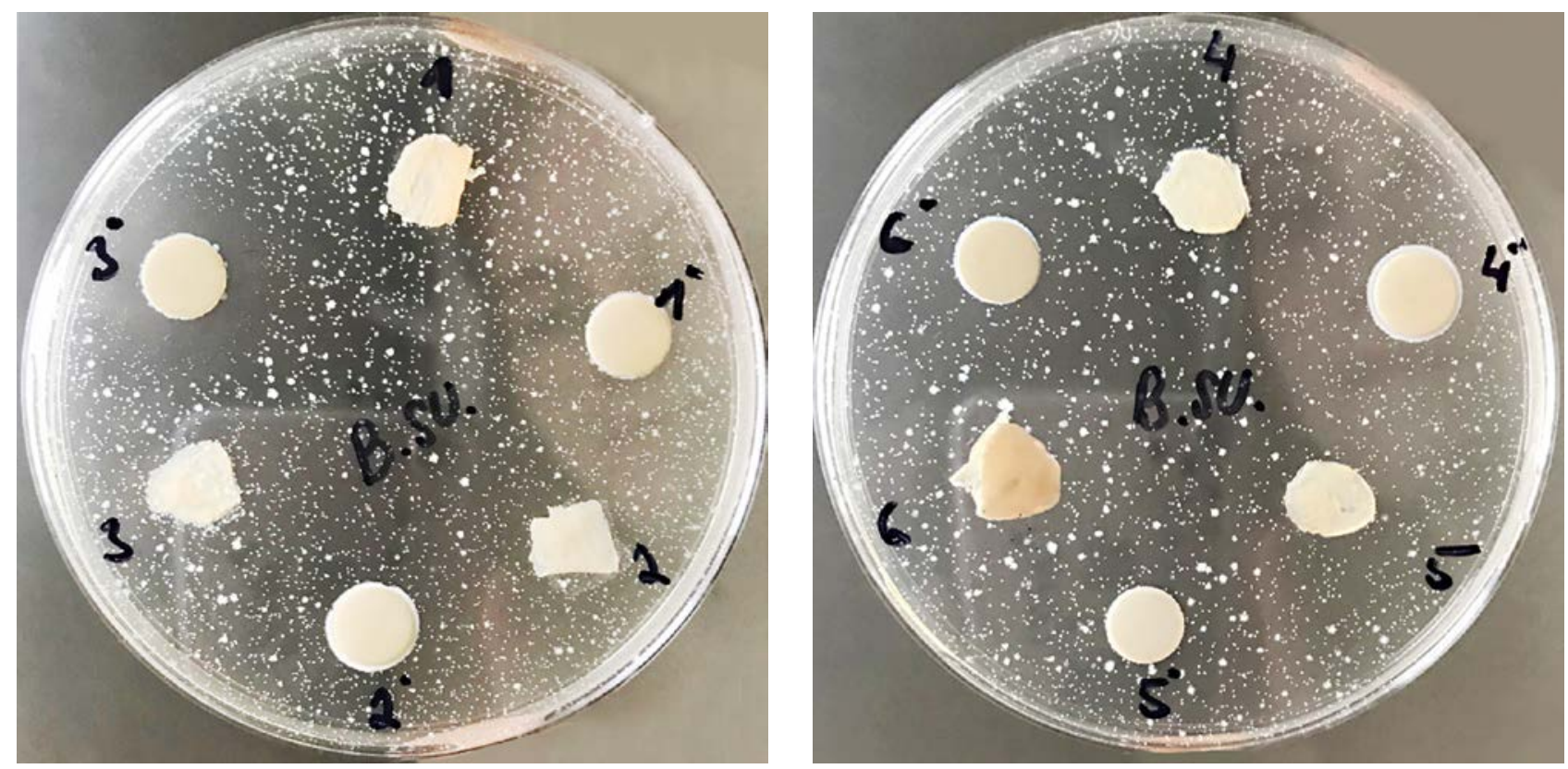

Fig. 3. Images showing the Bacillus subtilis plates post-incubation for sample numbers $1-6$ where no IZs are present except for sample number $3^{\circ}$ where juice was used as the matrix
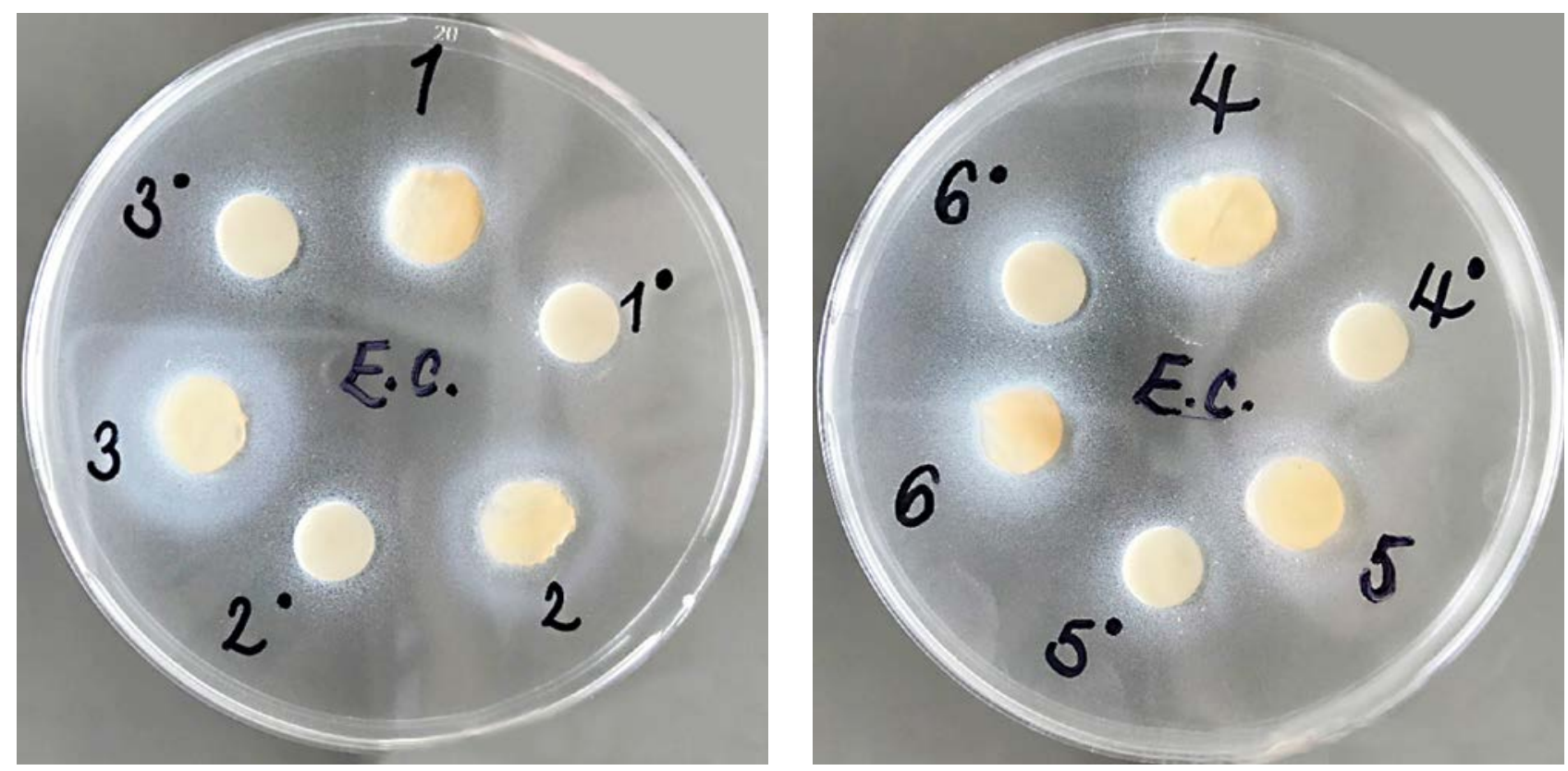

Fig. 4. Image showing the Escherichia coli plates post-incubation for sample numbers $1-6$ where IZs are present for sample numbers $2,4,5$ and 6 where muscle was the matrix used 

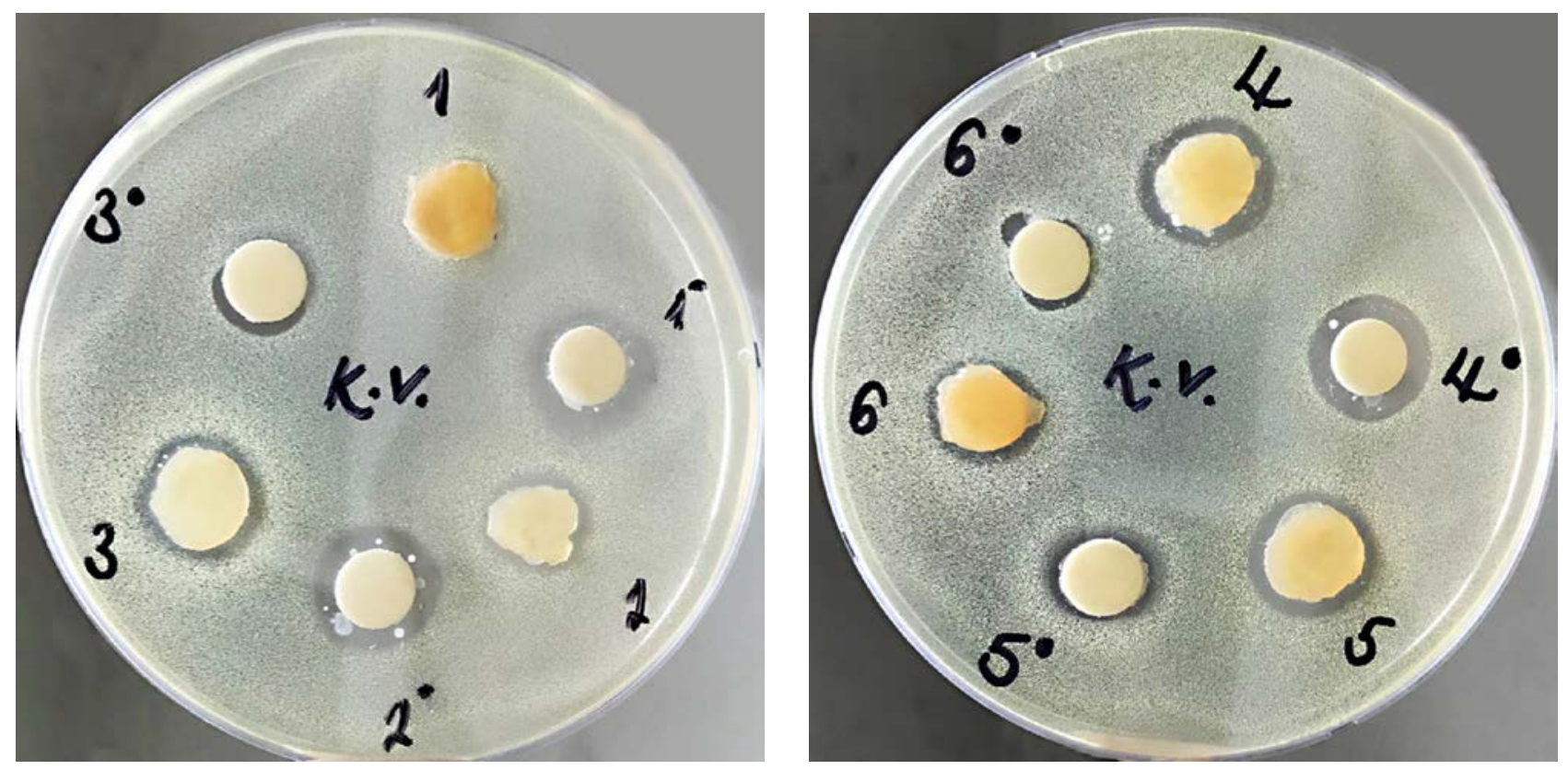

Fig. 5. Images showing the Kocuria rhizophila plates post-incubation for sample numbers $1-6$ showing IZs present for meat samples $2-6$ and for juice samples $1^{\bullet}-6^{\bullet}$

method may not detect certain antibiotics or prove less sensitive in relation to other methods (as seen by the validation studies performed in 2010 by $\mathrm{G}$ a u d i n et al. [7].

To promote this work, one could perform further experimentations of the same poultry products and samples with other screening methods for comparison. Additionally, the experiment using the STAR method could be repeated to determine if the same results are attained. Moreover, the STAR method could be evaluated in relation to a larger sample size. In relation to the effect of the matrix on the STAR method's performance, no experimentations or other studies have been performed and published which looked at using matrices other than muscle, like meat, juice and skin, using the STAR method. Given the discrepancies discussed, further experimentations are needed to ascertain whether other matrices can be validated for use in the STAR method so that reasonable conclusions can be drawn from the results.

\section{CONCLUSIONS}

This study concerned the broad-spectrum detection of antibiotic residues in poultry meat by a multi-plate assay via use of the STAR method. Families of antibiotics preidentified due to positive samples in the results of this work include aminoglycosides, beta-lactams, sulphonamides and macrolides. As a targeted confirmatory analysis was not performed, we are unable to determine where false positive and false negative results arose as given by the use of the STAR screening method. Therefore, to be able to draw any definitive conclusions from this study, further confirmatory analysis must be performed.

\section{ACKNOWLEDGEMENTS}

This study was supported by VEGA Grant No. 1/0576/17. We would also like to thank Daniela Juščáková, DVM, and Lisa Dunne, BSc,. for their help in completion of laboratory experiments and in sourcing samples.

\section{REFERENCES}

1. Centre for Science and Environment, 2014: Antibiotics in Chicken Meat: study. New Delhi: Pollution Monitoring Laboratory, 36 p. PML/PR-48/2014.

2. Cháfer-Pericás, C., Maquieira, Á., Puchades, R., 2010: Fast screening methods to detect antibiotic residues in food samples. Trends in Analytical chemistry, 29, 9, 1038-1049. DOI:10.1016/j.trac.2010.06.004. 
3. European Commission, 2002: Commission Decision 2002/ 657/EC of 12 August 2002 implementing Council Directive 96/23/EC concerning the performance of analytical methods and the interpretation of results. Official Journal of the European Communities, L. 221/8-36.

4. Ezenduka, E. V., Ike, O. S., Anaelom, N. J., 2014: Rapid detection of antimicrobial residues in poultry: A consequence of non-prudent use of antimicrobials. Health, 6, 2, 149-152. DOI: 10.4236/health.2014.62023.

5. Gaudin, V., Fuselier, R., 2002: Star protocol-Screening test for antibiotic residues. AFSSA Agence Française de Sécurité Sanitaire des Aliments-EU Community Reference Laboratory in Fougéres (France), LMV/UCM/P05/11.AN Version 2.

6. Gaudin, V., Maris, P., Fuselier, R., Ribouchon, J. L., Cadieu, N., Rault, A., 2004: Validation of a microbiological method: the STAR protocol, a five-plate test, for the screening of antibiotic residues in milk. Food Additives and Contaminants, 21, 5, 422-433. DOI: 10.1080/02652030410001667575.

7. Gaudin, V., Hedou, C., Rault, A., Verdon, E., 2010: Validation of a Five Plate Test, the STAR protocol, for the screening of antibiotic residues in muscle from different animal species according to the European decision 2002/657/EC. Food Additives and Contaminants, 27, 7, 935-952. DOI: 10.1080/19440041003677483.

8. Gondová, Z., Kožárová, I., Poláková, Z., Mad’arová, M., 2014: Comparison of four microbiological inhibition tests for the screening of antimicrobial residues in the tissues of foodproducing animals. Italian Journal of Animal Science, 13, 4, 728-734. DOI: 10.4081/ijas.2014.3521.

9. Guetiya Wadoum, R. E., Zambou, N. F., Anyangwe, F. F., Njimou, J. R., Coman, M. M., Verdenelli, M. C., et al., 2016: Abusive use of antibiotics in poultry farming in Cameroon and the public health implications (full paper). British Poultry Science, 57, 4, 483-493. Retrieved 15/01/2018 from Taylor and Francis online: https://www.tandfonline.com/loi/cbps20. DOI: $10.1080 / 00071668.2016 .1180668$.

10. Hao, H., Cheng, G., Iqbal, Z., Ai, X., Hussain, H. I., Huang, L., et al., 2014: Benefits and risks of antimicrobial use in foodproducing animals. Frontiers in Microbiology, 5, 288. DOI: 10.3389/fmicb.2014.00288.

11. Kožárová, I., Mačanga, J., Goldová, M., Major, P., Tkáčiková, S., 2011: Detection of maduramycin residues of chickens and pheasants by the screening test for antibiotic residues (STAR). Food Additives and Contaminants: Part A, 28, 5, 608-618. DOI: 10.1080/19440049.2011.561879.
12. Kožárová, I., Marcinčák S., Reitznerová, A., Bartkovský, M., Mačanga. J., Marcinčáková, D., et al., 2016: Verification for the presence of inhibitory substances in poultry meat after the consumption of the feed mixture supplemented with fermented feed. Potravinarstvo, Scientific Journal for Food Industry, 10, 1, 612-618. DOI: 10.5219/682.

13. Mund, M. D., Khan, U. H., Tahir, U., Bahar-EMustafa, Fayyaz, A., 2017: Antimicrobial drug residues in poultry products and implications on public health: A review. International Journal of Food Properties, 20, 7, 1433-1446. Retrieved 02/10/2017 from Taylor and Francis online: https://www.tandfonline. com/loi/ljfp20. DOI: 10.1080/10942912.2016.1212874.

14. Okerman, L., De Wasch, K., Van Hoof, J., 1998: Detection of antibiotics in muscle tissue with microbiological inhibition tests: effects of matrix. Analyst, 123, 2361-2365. DOI: 10.1039/A804903C.

15. Pikkemaat, M. G., 2009: Microbiological screening methods for detection of antibiotic residues in slaughter animals. Analytical and Bioanalytical Chemistry, 395, 893-905. DOI 10.1007/s00216-009-2841-6.

16. Pikkemaat, M. G., Rapallini, M. L. B. A., Dijk, S. O. V., Elferink, J. W. A., 2009: Comparison of three microbial screening methods for antibiotics using routine monitoring samples. Analytica Chimica Acta, 637, 1-2, 298-304. DOI: 10.1016/j. aca.2008.08.023.

17. Reyes-Herrera, I., Schneider, M. J., Cole, K., Farnell, M. B., Blore, P. J., Donoghue, D. J., 2005: Concentrations of Antibiotic Residues Vary between Different Edible Muscle Tissues in Poultry. Journal of Food Protection, 68, 10, 2217-2219. DOI: 10.4315/0362-028X-68.10.2217.

18. Van Boeckel, T. P., Brower, C., Gilbert, M., Grenfell, B. T., Levin, S. A., Robinson, T. P., et al., 2015: Global trends in antimicrobial use in food animals. Proceedings of the National Academy of Sciences of the United States of America, 112, 18, 5649-5654. DOI: https://doi.org/10.1073/pnas.1503141112.

19. Vishnuraj, M. R., Kandeepan, G., Rao, K. H., Chand, S., Kumbhar, V., 2016: Occurrence, public health hazards and detection methods of antibiotic residues in foods of animal origin: A comprehensive review. Cogent Food and Agriculture, 2. DOI: http://dx.doi.org/10.1080/23311932.2016.1235458.

Received May 4, 2019

Accepted July 10, 2019 